\title{
A review of Longman Dictionary of Contemporary English (6th edition)
}

\author{
Amy Chi ${ }^{1}$
}

Published online: 18 March 2016

(C) Springer-Verlag Berlin Heidelberg 2016

\begin{abstract}
Longman Dictionary of Contemporary English (6th edition) for advanced learners (LDOCE6), published by Pearson Education 2014, is the latest edition of this reputable dictionary for foreign learners of English. To increase its competitiveness, LDOCE6 includes new features like the Longman Communication 9000 to provide users with assistance on vocabulary acquisition, and the Grammar Guide to give information on major grammar topics and grammar notes that illustrate common grammar mistakes made by learners. This review examines whether the dictionary satisfies the needs and expectations of the users (in this case, advanced level EFL students); and if it rightly pitches at the level of their English proficiency and reference skills for ease of use and acquiring linguistic knowledge.
\end{abstract}

Keywords Pedagogical lexicography · Dictionary criticism - Dictionary use

\section{Introduction}

Longman Dictionary of Contemporary English (6th edition) for advanced learners (LDOCE6), published by Pearson Education 2014, is the latest edition of this reputable dictionary for foreign learners of English. Its appearance is lauded by supporters of print dictionaries who have been witnessing the dwindling options for print with the growing domination of electronic media in all aspects of life.

Although the various editions of the Longman Dictionary of Contemporary English are praised by users for innovation and quality of work over the years,

Amy Chi

lcamychi@ust.hk

1 Center for Language Education, Hong Kong University of Science and Technology, Clear Water Bay Road, Kowloon, Hong Kong 
LDOCE6 print now faces a generation of potential users that is bombarded with many choices, many of whom are very electronic savvy and are accustomed to receiving free services and information from cyberspace. To increase its competitiveness, LDOCE6 includes new features like the Longman Communication 9000 to provide users with assistance on vocabulary acquisition, and the Grammar Guide to give information on major grammar topics and grammar notes that illustrate common grammar mistakes made by learners. LDOCE6 also offers users free access to its website with more information on words, vocabulary practice exercises, videos and tests.

The question, however, remains: Are these new features appealing to the Dictionary's target users? A print dictionary like LDOCE6 has many inherent disadvantages: for example, its weight and size. And there is the practical concern of $\operatorname{cost}^{1}$ to most. Indeed, research on dictionary use continuously reveals the rudimentary search skills and dictionary use knowledge of many users, including students and teachers of English (Chi 2013; Bae 2015). Additionally, with many competing EFL dictionaries offering features with striking resemblance (Akasu 2013), it would be interesting to examine whether LDOCE6 will appeal to its potential buyers. Surely, the answer will be obtained from its sales performance and/ or user research in due course but the question can also be explored now based on existing dictionary information and some reasonable suppositions.

The dictionary will be examined on whether it satisfies the needs and expectations of the users (in this case, advanced level EFL students); and if it rightly pitches at the level of their English proficiency and reference skills for ease of use and acquiring linguistic knowledge.

To make a purchasing decision, common strategies for an average user include comparing what the new edition has to offer with its previous editions, and/or with other rival dictionaries. In the former case, the simplest or direct way to compare two editions of the same dictionary would be to read what the dictionary says about itself in the front matter articles like the dictionary's introduction, often prepared by the dictionary's main editors, and where they normally state the edge or selling point of the latest edition. Another part of the dictionary giving similar information would be the description shown on the back (dust cover) of the dictionary.

\section{Description of the new edition's features on the back cover}

With limited knowledge of and training in dictionary use, most students, and/or parents, would make a decision based on the obvious facts and concepts they could understand. A possible criterion in the case of a student is:

Student: I focus on the numbers shown: words and examples. Is it not right to expect a new edition to have more words, especially new words, and examples

\footnotetext{
1 The list price of the new Longman Dictionary of Contemporary English (Paper and Online Access), 6th Edition at Amazon.com is US\$60 to date.
} 
than the previous? Also, I look if there are any new functions that the dictionary offers to solve my study problems.

To this end, the student would be disappointed since most of the numbers on LDOCE6 remain the same as shown in the 5th edition (Longman Dictionary of Contemporary English 2009). The following are numbers which appear both in the 5th and 6th editions:

\begin{tabular}{lc}
\hline The print & On-line \\
\hline 230,000 words, phrases, and meanings & 300,000 words, phrases and meanings \\
165,000 corpus-based examples & 88,000 pronounced examples and one million additional \\
& corpus examples \\
Integrated Thesaurus with over 18,000 & 147,000 collocations $+48,000$ synonyms, antonyms, and \\
synonyms, antonyms, and related & related words \\
words & \\
65,000 collocations & \\
\hline
\end{tabular}

The only change in number found in LDOCE6 is in Longman Communication 9000 (LC9000) and it is stated that the new edition subsumes the "3000 most frequent words in spoken and written English" as shown in LDOCE5. LC9000 also includes "updated core vocabulary" and this would, it is assumed, satisfy the student's criterion on new words.

At this point, some may quickly discard such superficial and rudimentary criteria in judging the new LDOCE6 but many would agree that there are plenty of such potential users whose dictionary knowledge is at such a basic level. Indeed, the dictionary has unnecessarily invited such comparison by providing the same information (the numbers) on both the editions. If the dictionary removes the repetition of information, the space vacated could be used to provide more explanation on the LC9000, which is the major feature of this new edition as illustrated in the dictionary's "Introduction". Currently, information on LC9000 provided in the blurb is unclear, if not overtaxing, and contains many concepts. It states,

"Longman Communication 9000: updated core vocabulary, including the 3000 most frequent words in spoken and written English, show which words to learn first."

It may be clear to students that an English dictionary is a book about English words, but concepts such as core vocabulary, word frequency in EFL vocabulary acquisition, differences between spoken and written English, and a later point which suggests the dictionary's 2000 Common Words, are not built-in concepts in most EFL teaching, which generally adopts a communicative approach.

The blurb also highlights that the dictionary includes "register notes [which] focus on the differences between spoken and written English so you always choose the right word". Such a description can be confusing and/or misleading. First, with 
experience as an EFL teacher at tertiary level in Asia, I will say the term register is not commonly used at school level, so it would not be understood by most students. At university, some EAP classes will introduce the concept, but often, terms like academic English or formal and informal English are used instead. Second, the phrasing of the sentence may also mislead students into believing that using 'the right word' only ties in with the spoken or written mode of the language.

Also, 'register' as a linguistic term covers more ground than just differences between spoken and written English. According to the Dictionary of Lexicography (Hartmann and James 1998), the word refers to "a variety of language associated with a particular situation context, such as an occupation or social activity". Since LDOCE6 also uses labels like taboo, literary and AmE to provide information on the register of words, such use of terminology could be confusing.

The description on the back cover of the dictionary most probably is the first contact point of a potential user with the dictionary and the above discussion suggests that LDOCE6 has been short-changed by such coverage. A better understanding of the dictionary's target users' linguistic knowledge, or lack thereof, would help the dictionary to better attract this group of potential users. For example, "Grammar notes" and "Grammar Guide", two new features highlighted in this new edition of LDOCE as shown on the back cover, are features that would pose no problem in understanding from an EFL learner's perspective. Indeed, LDOCE6 offers precise information which meets the need of its users. For example, after the entry 'regarding', the dictionary offers further grammatical information on the word and its synonyms 'concerning and with regard to'. These would be the features which deserve more illustration than they are given at present.

\section{Dictionary information on the front matter}

Landau (1989) argues that the attention reviewers often give to the front-matter articles of a dictionary has made the articles "of considerable commercial importance" (116). To the untrained eyes of students, it can be seen that two new items have been added to the Labels of this new edition and they are 'approving' and 'disapproving'. LDOCE6's inclusion of these two labels is welcome given that pragmatics is often the focal point of discussion in class for learners at advanced level. The dictionary explains what kind of linguistic assistance these labels in general offer but it would be more helpful if examples were provided. Furthermore, a close examination of words with these two labels indicates inconsistencies which may confuse students. First, the two labels do not follow the convention of presentation used by the other labels in this dictionary. Other labels such as formal or technical appear in entries in italic form right after the grammatical information, for example, the words aggregate ${ }^{1}$ and exalt carry the label formal. 


\section{ag-gre-gate ${ }^{1}$ /'ægrigət/ AWL $n$ formal 1 [C] the total} after a lot of different figures or points have been added together: [+of] The smaller minorities got an aggregate of 1,327 votes. | In the aggregate (=as a group or in total), women outlive men by 7 or more years. | on aggregate BrE (=when the points from two football games are added together) Manchester United won 2-1 on aggregate. 2 [singular, U] technical sand or small stones that are used in making CONCRETE

ex-alt /ig'zo:lt \$-'zb:lt/ $v[T]$ formal 1 to put someone or something into a high rank or position $\mathbf{2}$ to praise someone, especially God: Exalt ye the Lord.

Instead of following such a convention, the usage information on the words with 'approving' or 'disapproving' labels appears as part of the definition introduced by a dash. For example, see the entries of feisty and narcissism below.

feist:y /'farsti/ adj having a strong determined character and being willing to argue with people - use this to show approval: Difranco charmed the audience with her feisty spirit. THESAURUS DETERMINED

nar-cis-sis"m /'na:sisizəm \$ 'narr-/ $n$ [U] when someone is too concerned about their appearance or abilities or spends too much time admiring them - used to show disapproval: He went to the gym every day, driven purely by narcissism. -narcissist $n[C]$-narcissistic /,na:sə'sIstrk4 $\$$, narr-/ adj

A further check of other words in LDOCE6 indicates that such information given to words in fact already exists in LDOCE5, for example, in words like newfangled, obsessive ${ }^{1}$, aggrandizement and complacent. Based on the results of the several words under examination, LDOCE6 indeed has offered no change in this area other than the inclusion of the two labels on the label list in the front matter.

A layperson who compares the front matter of the two editions will also notice that a part of information which is shown in LDOCE5 is missing in the front matter of LDOCE6. On the page with the heading 'Contents' in the dictionary, a whole section marked as 'Formality in spoken English 1-2043, A2-A16' in LDOCE5 has been reduced to 'Language supplement (see middle section page A1)'. 
From a learner's perspective, I believe the dictionary is doing itself a disfavor with such a change. The information given in the sections under 'Formality in spoken English' is relevant to learners' needs, and is comprehensible to most learners, who would have limited linguistic knowledge. Instead of telling the users 'these words are good for you' or 'you will need to learn' which the blurb keeps repeating, these dictionary pages are self-explanatory and appealing to users with examples on topics of functional language to express 'agreeing, disagreeing, apologizing, opinions, requests, suggestions, hello, goodbye and thank you' in formal and informal situations. Most average users of the dictionary would be able to relate to the dictionary's metalanguage at this level, and, in turn, appreciate its value. It is true that the information is still provided for users in the LDOCE6 but it is a pity that these pages are not highlighted by the dictionary makers, especially when there is plenty of empty space on the 'contents' page.

Print errors also appear on page 2126 when the dictionary explains what Longman Communication 9000 is for. On the second column of the page, the dictionary cites the word acquire as an example (see below).

\section{Take for example the verb acquire. It is marked as $\bullet \bullet-$ w3 which means that it is in the top 3000-6000 words in English as a whole, and more specifically one of the top 3000 words in written English. Note that it has no marker for}

The first error is that if a word has three circles, according to LDCOE 6 on the same page, it belongs to the 3000, not 3000-6000, most frequent words. Second, the word acquire is shown with three circles and a W3 label here but this contradicts information the same dictionary gives to the word in the word entry-two circles and a W2 (see below).

ac-quire /ə'kwaiə \$ ə'kwair/ 00 W2 AWL $v[\mathrm{~T}]$

1 formal to obtain something by buying it or being given it: Manning hoped to acquire valuable works of art as cheaply as possible. | The council acquired the land using a compulsory purchase order. THESAURUS BUY

$\mathbf{2}$ to get or gain something: The college acquired a reputation for very high standards.

Since LDOCE5 also gives the word a W2 label, there is reason to believe that the information given in LC9000 is an error. Information on the word buy, which is shown as the synonym of acquire, is also confusing. It was labeled with two circles on page 2126 but with three in the word entry of the dictionary [see below]. As a feature under the spotlight in this new edition, such errors found in the illustration of LC9000 are very conspicuous. 


\section{buy $^{1} /$ bai/ 00 S1] W1 $v$ (past tense and past participle bought /bot \$ bo:t/) \\ 1a) $[I, T]$ to get something by paying money for it OPP sell: Where did you buy that dress? | Ricky showed her the painting he'd bought that morning. | buy sb sth Let me buy you a drink. | buy sth for sb/sth The money will be used to buy equipment for the school. | buy (sth) from sb It's cheaper to buy direct from the manufacturer. | buy sth for $\$ 10 / € 200$ etc Dan bought the car for $\$ 2,000$. I It's much cheaper to buy in bulk (=buy large quantities of some- thing). b) [T] if a sum of money buys something, it is enough to pay for it: $\$ 50$ doesn't buy much these days. | buy sb sth $\$ 15$ should buy us a pizza and a drink.}

It is possible that LDOCE6 will not score well from average learners after an initial check on the dictionary's front matter and back cover and comparing the information given to them on LDOCE6 and 5 on these pages. Most of the issues discussed, however, should not affect the pedagogical value and overall lexicographic quality of the new edition; but from a dictionary use research perspective, how the dictionary is perceived by its target users is a cause for concern.

\section{Information on word entries}

This part of the review has chosen ten words from the teaching material of a third year university ESP course to students majoring in Humanities and Social Science to check if the dictionary can support its claim to provide users help with academic studies. The words chosen for examination are related to the course assessment which requires students to review academic journal articles and prepare a literature review on a certain topic. In the course, students would have to tackle the following words:

Action verbs-maintain, claim, contend, postulate and surmise.

Content words from reading passages-hegemony, discourse, regime, nuanced, lampooning.

The search results reveal LDOCE6 to be a quality piece of lexicographical work-with precise and clear definitions of the words in question. For example, the word nuanced is shown as a derivative in the noun entry of nuance. The dictionary definition on the noun is clear and a related word 'subtlety' is given to help users further grasp the meaning of the word. The derivative nuanced is clearly labeled with its word form (adjective) and a phrase is given to demonstrate its use-'a skilful and nuanced performance'. Such information would surely help students understand the course-assigned reading in which the word was used as below: 
The article notes that nuanced readings of China's historical relations with its East Asian neighbors provide a critical entry into a more sophisticated analysis of popular declarations of "Chinese exceptionalism" (Callahan 2012).

Also, the Grammar notes given to the word claim ${ }^{1}$ affirm the value of such a new feature. They not only prompt users to be aware of register, but also the corresponding grammatical structure required (see entry below).

\section{GRAMMAR}

\section{In more formal English, you say it is claimed that something is true: It has been claimed that he was difficult to work with.}

The extension of Longman 3000 to Longman 9000 has impacted two of the ten words under search; they are contend and discourse ${ }^{1}$. The two words are now presented in red and given one circle, which implies they belong to the range of 6000-9000 most frequent words according to LDOCE6. Given their frequent appearance in journal articles associated with students of the aforementioned disciplines, such change is fair and informative, and hence welcome to users.

In this small-scale search, LDOCE6 is found to meet the needs of the subject users (EFL university students). In addition to precise and clear definitions, all the ten words under search are given either labels to indicate their academic status (with the insertion of the label AWL or formal), or circles to show their relative high frequency of use (LC9000); and such features help students to be better-informed in vocabulary learning and use. Such additional features surely add value to an already high-quality lexicographical publication.

\section{References}

Akasu, K. 2013. Methods in dictionary criticism. In The Bloomsbury Companion to Lexicography, ed. H. Jackson, 48-62. London \& New York: Bloomsbury.

Bae, S. (2015). A course in dictionary use for Korean EFL teachers. Lexicography: Journal of ASIALEX: 2(1). doi:10.1007/s40607-015-0017-4.

Callahan, W. A. (2012). Sino-speak: Chinese exceptionalism and the politics of history. Journal of Asian Studies: 71(1). doi:10.1017/S0021911811002919.

Chi, M.L.A. 2013. Researching pedagogical lexicography. In The Bloomsbury Companion to Lexicography, ed. H. Jackson, 165-187. London \& New York: Bloomsbury.

Hartmann, R.R.K., and G. James. 1998. Dictionary of Lexicography. London: Routledge.

Landau, S.I. 1989. Dictionaries: The Art and Craft of Lexicography. Cambridge: Cambridge University Press.

Longman Dictionary of Contemporary English (Fifth edition). (2009). Harlow: Pearson Education Limited. 